\title{
Preview: 2019 Materials Research Society Fall Meeting \& Exhibit
}

\author{
Hynes Convention Center and Sheraton Boston Hotel, Boston, Massachussetts \\ Meeting: December 1-6 • Exhibit: December 3-5 • mrs.org/fall2019
}

$\mathrm{T}^{\mathrm{n}}$ he Materials Research Society (MRS) will hold its 2019 MRS Fall Meeting and Exhibit at the Hynes Convention Center and the Sheraton Boston Hotel in Boston, Mass., December 1-6. The Meeting will include technical programming, tutorials, an award ceremony, poster sessions, a career fair, and other special activities.

MRS meetings focus on leading interdisciplinary materials research in both fundamental and applied areas, coordinated by more than 200 scientists from both academia and industry worldwide. The Meeting's core is its technical program, which includes 54 symposia that are organized into eight clusters.

\section{Symposium clusters}

Broader Impact includes a symposium on Materials Data Science-Transformations in Interdisciplinary Education. Topics will include interdisciplinary communications, teaching data science skills at the undergraduate and graduate levels, and data life cycle and duration.

The Electronic, Photonic and Magnetic Materials cluster focuses on a broad range of advanced functional materials for electronics, multiferroics, and magnetoelectrics. The five symposium topics range from emerging material platforms and approaches for plasmonics, metamaterials, and metasurfaces to molecular and organic ferro- and piezoelectrics.

The Energy and Environment cluster includes 17 selected topics that highlight everything from challenges in battery technologies for next-generation electric vehicles, to green electrochemical energystorage solutions, and nanomaterials for sensing and control of energy systems.

The Fabrication of Functional Materials and Nanomaterials cluster covers six topics from $2 \mathrm{D}$ materials beyond graphene, to crystal engineering of functional materials, to advanced atomic layer deposition.

The Materials for Quantum Technology cluster features three symposia on materials for quantum computing applications, coherent and correlated magnetic materials for hybrid quantum interfaces, and predictive synthesis and advanced characterization of emerging quantum materials.
Materials Theory, Computation and Characterization features seven symposia that cover diverse topics such as advanced atomistic algorithms, using machine learning in high-throughput discovery of new materials, and in situ/operando studies of dynamic processes in ferroelectric, magnetic, and multiferroic materials.

Mechanical Behavior and Structural Materials includes four symposia that cover a diverse range of topics, including extreme mechanics, high-entropy alloys and other novel high-temperature structural alloys, and mechanics of nanocomposites and hybrid materials.

The Soft Materials and Biomaterials cluster has 11 symposia that focus on advanced neural materials and devices, bioelectrical interfaces, hydrogel materials, and bringing mechanobiology to materials.

\section{Plenary session and awards}

The Plenary Session Featuring The Fred Kavli Distinguished Lectureship in Materials Science presentation will be held on Monday, December 2, at 6:30 $\mathrm{pm}$ in the Sheraton Boston Hotel, Grand

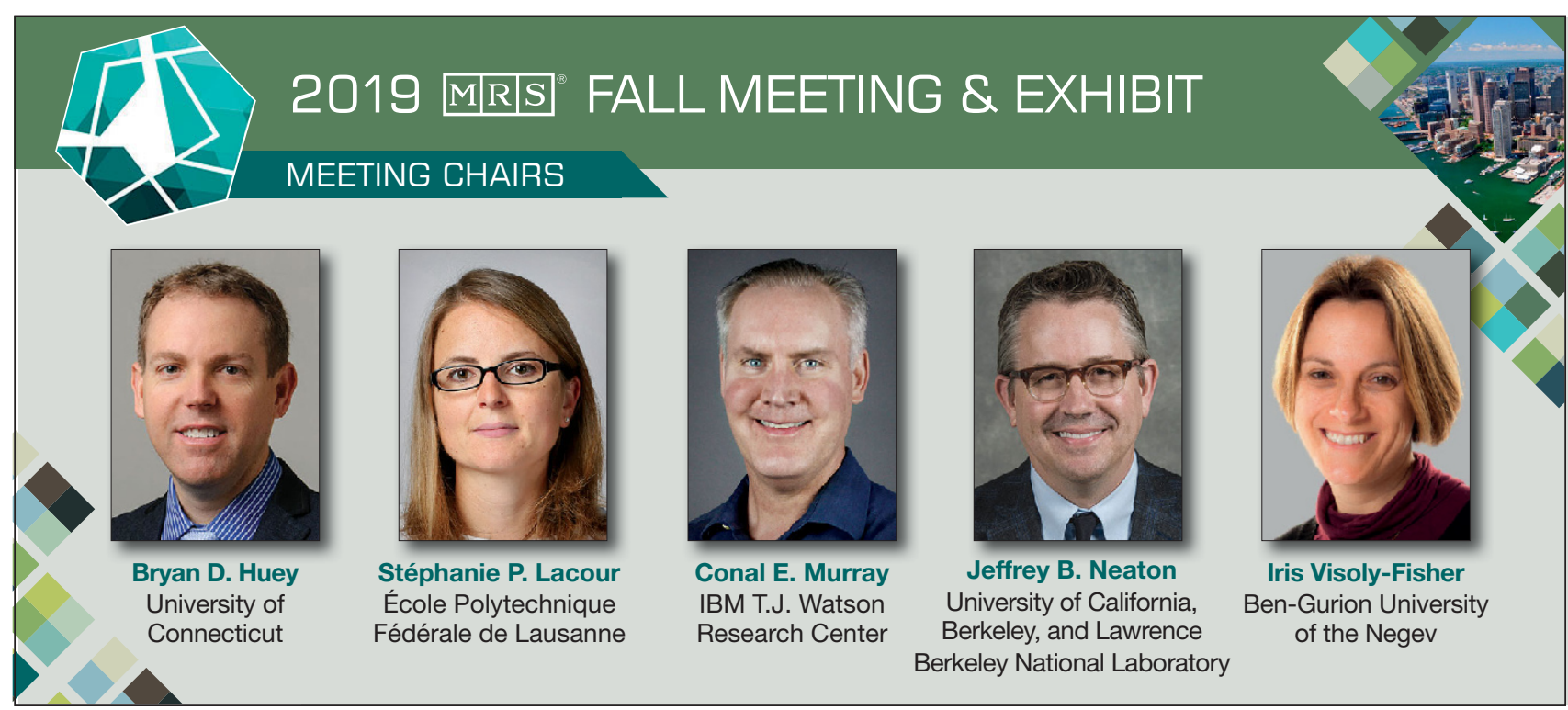


Ballroom. This year's plenary speaker is Sharon C. Glotzer, University of Michigan.

The MRS Awards and Recognition Program Featuring the Von Hippel Presentation will convene on Wednesday, December 4, from 5:30 pm to 7:30 $\mathrm{pm}$ in the Sheraton Grand Ballroom. The Von Hippel Award, David Turnbull Lectureship, MRS Medal, Materials Theory Award, The Kavli Foundation Early Career Lectureship in Materials Science, the MRS Nelson "Buck" Robinson Science and Technology Award for Renewable Energy, MRS Bulletin Postdoctoral Publication Prize, MRS Postdoctoral Awards, Graduate Student Gold and Silver Awards, and the Arthur Nowick Graduate Student Award will be presented. For up-to-date award recipient information, visit mrs.org/fall2019.

Join us for an evening of Special Talks and Panel Discussion Featuring MRS Award Recipients on Tuesday, December 3, at 6:15 pm. This event will feature flash talks (10-minute summaries explaining current research topics) from the following 2019 MRS Fall Meeting Award recipients: EU-40 Materials Prize (E-MRS Award); The Kavli Foundation Early Career Lectureship in Materials Science; Materials Theory; MRS Medal; and David Turnbull Lectureship.

\section{Special sessions and events}

Symposium $\mathbf{X}$ talks provide Meeting attendees with an overview of leadingedge topics. Featured speakers are Brian Litt, University of Pennsylvania (Monday); Evelyn Wang, Massachusetts Institute of Technology (Tuesday); Francesco Stellacci, École Polytechnique Fédérale de Lausanne (Wednesday); and Alessandra Lanzara, Lawrence Berkeley National Laboratory and University of California, Berkeley (Thursday).

Artificial intelligence/machine learning is featured in two LATE NEWS-HOT TOPIC symposia for the Fall Meeting: MT02, Closing the Loop-Using Machine Learning in High-Throughput Discovery of New Materials; and MT03, Automated and Data-Driven Approaches to Materials DevelopmentBridging the Gap Between Theory

\section{HOTELS IN BOSTON}

MRS receives meeting space at a greatly discounted rate as a result of contracting a large block of sleeping rooms at the official meeting hotels. In order to keep meeting costs as low as possible and minimize the financial risk to MRS, we encourage you to utilize official MRS housing while you are attending an MRS meeting.

Hotels offering discounted rates for the Meeting are listed below. When making your reservation, please make sure you are doing so through the 2019 MRS Fall Meeting website at mrs.org/fall2019/hotels. *

- Sheraton Boston Hotel 39 Dalton St., Boston, Mass. 02199 617.236 .2000 or 888.627 .7054 Group Rate: \$212 single, \$222 double Additional persons: \$20 ea. * * Deadline: November 11, 2019

- Boston Marriott Copley Place 110 Huntington Ave., Boston, Mass. 02116 617.236.5800

Group rate: \$206 single, \$223 double, Additional persons: $\$ 20$ ea. * * Deadline: November 6, 2019

- The Westin Copley Place 10 Huntington Ave., Boston, Mass. 02116 617.262 .9600

Group Rate: \$208 single, \$218 double Additional persons: $\$ 20$ ea. * * Deadline: November 8, 2019

- The Colonnade Hotel 120 Huntington Ave., Boston, Mass. 02116 617.424 .7000 Group Rate: \$209 single, \$209 double, \$239 triple, \$269 quad** Deadline: November 11, 2019
- Hilton Boston Back Bay Hotel 40 Dalton St., Boston, Mass. 02115 617.236 .1100 Group Rate: \$219 single/double, $\$ 239$ triple/quad** Deadline: November 8, 2019

- Boston Park Plaza 50 Park Plaza at Arlington St., Boston, Mass. 02116 800.225 .2008 or 617.426 .2000 Group Rate: $\$ 180$ single, $\$ 200$ double, $\$ 220$ triple, \$240 quad* * Deadline: November 8, 2019

- Embassy Suites Boston at Logan Airport 207 Porter St., Boston, Mass. 02128 617.567 .5000 Group Rate: $\$ 159$ single Additional persons: $\$ 10$ ea. * Deadline: November 10, 2019

* Unofficial housing bureaus have contacted exhibitors and potential attendees and/or created websites with housing options. These companies are not affiliated with the 2019 MRS Fall Meeting. Only the MRS website will have official housing for the Meeting.

** plus applicable taxes and fees

\section{mrs.org/fall2019/hotels}

and Industry. In addition, a Quantum Materials Panel Discussion, organized jointly among the three symposia (MQ01, MQ02, MQ03) in the Materials for Quantum Technology cluster, is planned for Wednesday, December 4, from 3:30 pm to 5:00 pm in Room 202 of the Hynes Convention Center.

Essentials of Getting Your Work Published, a professional development offering, is planned as a Hub Stage event on Sunday, December 1.

Poster sessions will be held in the evenings. The Meeting chairs will award prizes of up to $\$ 500$ for the best posters during each evening session.

The Materials Voice Booth will be in The Hub-Hall D on Tuesday and Wednesday from 11:00 am to 5:30 pm and Thursday from 10:00 am to 1:30 pm. Tell your US legislators why support of the physical sciences and science education is necessary - for national security, quality of life, and a strong economy. We invite you to utilize Materials Voice to ensure your message is heard on science policy issues.

The Government Affairs Committee will host Research Funding 
Opportunities sessions on Tuesday and Thursday. These sessions provide interaction between government agency presenters and the MRS Membership. Invited talks will be followed by roundtable Q\&A sessions with individual program managers.

The Congressional Science and Engineering Fellowship Program Information Session will be held on Tuesday, December 3, from 4:15 pm to 5:15 pm. MRS offers exciting opportunities for scientists to learn about the field of science policy by spending one year as a special legislative assistant in the US Congress in Washington, DC. Come learn about the MRS/OSA and MRS/TMS Congressional Science and Engineering Fellowships and hear from current and former Fellows about their experiences as scientists in the US Senate and House of Representatives.

The iMatSci Innovation Showcase provides a platform for independent technology leaders and those at universities, research laboratories, and startup companies to demonstrate the practical applications of their materialsbased technologies. The entities behind these innovations will generally be prerevenue and seed-stage innovators that are actively seeking partners, funding, or avenues for moving toward product commercialization. iMatSci will take place on Tuesday, December 3, from 8:00 am to 9:30 pm.

Green Cards for Scientific Researchers: How to Win Your EB-1/ NIW Case will take place on The Hub Stage-Hall D on Tuesday from 12:00 pm to $12: 45 \mathrm{pm}$. This presentation will cover and compare the criteria for EB-1A classification for foreign nationals of extraordinary ability in the sciences; EB-1B classification for foreign nationals who are outstanding researchers and professors; and the National Interest Waiver ("NIW") Category.

Throughout the week, Science in Video (SciVid), a high-impact materials science video competition, will showcase the finalists as they compete for recognition and prizes. Members will be asked to vote on their favorite videos from the SciVid
Competition finalists to determine the People's Choice winner. A viewing station will be located at the Public Outreach Center in The Hub-Hall D and in several locations throughout the Meeting. The SciVid awards presentation will take place on The Hub Stage on Wednesday, December 4, at 1:00 pm. For more information, visit mrs.org/sci-vid.

Creating an Effective IP Strategy: What Startups Need to Know will be held in the Sheraton, Constitution A, from 12:00 pm to $12: 45 \mathrm{pm}$ on Tuesday.

The Meeting will also include the Women's Workshop and Reception (Sunday, December 1) and the Women in Materials Science \& Engineering Breakfast (Wednesday, December 4). Additional information will be available via the MRS website and the MRS Meeting App. Preregistration is required.

The Careers at Government Laboratories and User Facilities-Panel Discussion will be held on The Hub Stage-Hall D on Monday, December 2 (4:30 pm-5:30 pm). This discussion is intended for students and early-career

\begin{tabular}{|c|c|c|c|}
\hline \multicolumn{4}{|c|}{$\begin{array}{l}\text { The } 2019 \text { MRS Fall Meeting will feature } 13 \text { tutorials held on } \\
\text { Sunday, December 1, Hynes Convention Center, Level } 2 \text {. } \\
\text { Tutorials cover a variety of topics to complement the symposium sessions and are free of charge for all registered attendees. } \\
\text { Tutorial notes will be available for purchase at the preregistration price of } \$ 35 \text { until November } 15 \text {. After the preregistration period } \\
\text { ends, notes will be available for purchase for } \$ 45 \text { on Sunday at Registration and then at the MRS/Cambridge Publications Booth } \\
100 \text { in the Exhibit Hall during Exhibit hours. }\end{array}$} \\
\hline \multirow[t]{2}{*}{ EL01 } & \multirow{2}{*}{$\begin{array}{l}\text { Optical Metasurfaces- } \\
\text { Materials, Designs and Advanced Applications } \\
\text { 8:30 am-5:00 pm }\end{array}$} & FF03 & $\begin{array}{l}\text { Aggregation-Induced Emission } \\
8: 30 \mathrm{am}-5: 00 \mathrm{pm}\end{array}$ \\
\hline & & \multirow{2}{*}{ FF06 } & \multirow{2}{*}{$\begin{array}{l}\text { Advanced Manufacturing and Computational } \\
\text { Tools for Reactive Materials Science } \\
\text { 8:30 am-5:00 pm }\end{array}$} \\
\hline EL04 & $\begin{array}{l}\text { Introduction to Chalcogenide Discovery and Design } \\
8: 30 \mathrm{am}-12: 00 \mathrm{pm}\end{array}$ & & \\
\hline \multirow[t]{2}{*}{ EN08 } & \multirow{2}{*}{$\begin{array}{l}\text { Processing and Device Optimization Strategies for } \\
\text { High Efficiency Solar Cells } \\
\text { 1:30 pm-5:00 pm }\end{array}$} & Ma01 & $\begin{array}{l}\text { Introduction to Quantum Spintronics } \\
\text { 1:30 pm-5:00 pm }\end{array}$ \\
\hline & & Mnn? & Introduction to Ion Trap and Superconducting Qubits \\
\hline \multirow[t]{2}{*}{ EN11 } & \multirow{2}{*}{$\begin{array}{l}\text { Silicon Photovoltaics- } \\
\text { Device Concepts, Materials and Interfaces } \\
\text { Engineering, Fabrication, Testing and Applications } \\
1: 30 \mathrm{pm}-5: 00 \mathrm{pm}\end{array}$} & MIOUL & $\begin{array}{l}\text { and Their Material Challenges } \\
8: 30 \mathrm{am}-12: 00 \mathrm{pm}\end{array}$ \\
\hline & & MT02/ & $\begin{array}{l}\text { Applied Machine Learning for } \\
\text { Materials Research and Development }\end{array}$ \\
\hline \multirow[t]{2}{*}{ EN17 } & \multirow{2}{*}{$\begin{array}{l}\text { Nuclear Materials and Damage- } \\
\text { Design and Impact } \\
\text { 1:30 pm-5:00 pm }\end{array}$} & & $8: 30 \mathrm{am}-5: 00 \mathrm{pm}$ \\
\hline & & MT04 & $\begin{array}{l}\text { Advanced Materials Exploration with Neutrons } \\
\text { 8:30 am-5:00 pm }\end{array}$ \\
\hline FF01 & $\begin{array}{l}\text { Advances in Large-Scale Synthesis of Beyond } \\
\text { Graphene 2D Materials } \\
\text { 1:30 pm-5:00 pm }\end{array}$ & SBO6 & $\begin{array}{l}\text { Molecules and Materials in Mechanobiology } \\
\text { 1:30 pm-5:00 pm }\end{array}$ \\
\hline
\end{tabular}


professionals interested in learning more about potential career paths at national laboratories.

The How to Develop an Effective Proposal for User Facilities workshop on Tuesday, December 3 (4:00 pm-8:00 $\mathrm{pm}$ ), will help guide students through the proposal writing process to conduct research at a user facility or national laboratory. Representatives from various user facilities and students who have already completed research will give advice to prospective students regarding the submission process, seeking funding, and preparation for their visit.

The How to Prepare for Your ABET Accreditation session will help materials departments prepare for their ABET visit. The training will be held on Tuesday, December 3, from 7:15 pm to 9:30 $\mathrm{pm}$, and the session may be attended without registering for the Meeting. Remote access will be available if unable to attend in person. Preregistration is recommended via mrs.org/ABET-training.

Meet Your New Faculty CandidatePoster Session is a new poster session being held in The Hub-Hall D on Wednesday, December 4 (4:00 pm-7:00 pm), for those who are seeking a faculty position. This poster session will offer a unique and interactive setting that will help faculty candidates and recruiting departments find their best matches more efficiently. Faculty candidates registered for the MRS Fall Meeting are invited to submit an abstract for this poster session by October 15, 2019. Search committees and current faculty are encouraged to attend to meet this year's faculty candidates. Additional information is available at mrs.org/fall2019/ meet-your-new-faculty-candidate.

The Frontiers Reception-Building Communities featuring PowerPoint Karaoke will be held on Thursday, December 5. Attendees are invited to participate in PowerPoint Karaoke from 5:30 pm to 6:45 pm, where they can showcase their research in an interactive and fun way. Preregister to be a presenter or submit a slide. Information can be found at mrs.org/fall2019/powerpoint-karaoke.

Following PowerPoint Karaoke, from 7:00 pm to 8:00 pm, attendees can join in the Frontiers Reception-Building

\section{MRS FALL MEETING REGISTRATION RATES}

\begin{tabular}{|l|c|c|}
\hline & $\begin{array}{c}\text { PREREGISTRATION } \\
\text { before 11:59 pm (ET) } \\
\text { November 15, 2019 }\end{array}$ & $\begin{array}{c}\text { ON-SITE REGISTRATION } \\
\text { after 11:59 pm (ET) } \\
\text { November 15, 2019 }\end{array}$ \\
\hline Meeting Registration & $\$ 750$ & $\$ 890$ \\
\hline Meeting Registration with MRS Member Discount & $\$ 590$ & $\$ 740$ \\
\hline Student Registration (Proof of student status required.) & $\$ 180$ & $\$ 210$ \\
\hline Student Registration with MRS Member Discount & $\$ 140$ & $\$ 170$ \\
\hline Retired & $\$ 190$ & $\$ 215$ \\
\hline Unemployed & $\$ 160$ & $\$ 200$ \\
\hline
\end{tabular}

2019 MRS Fall Meeting registration includes a complimentary one-year membership to MRS beginning January 1, 2020, through December 31, 2020.

Communities. "Quantum! Sustainability! Artificial Intelligence! Bio! Responsive \&Adapaptive Materials!YOUR Emerging Areas of Interest!" Will these emerging frontiers change the process of materials research? Help MRS chart a course to build new materials communities. Be a part of this interactive brainstorming mixer. Appetizers and beverages are included.

During the Real-Life Challenges and Opportunities in Sustainable Product Design Seminar, attendees will learn how to incorporate sustainability principles into research in a more comprehensive way while considering real-world applications in product design and manufacturing. This popular seminar will be held on Sunday, December 1, from 6:30 pm to 7:30 pm and Tuesday, December 3, from 5:30 pm to $6: 30 \mathrm{pm}$, and is aimed at materials researchers at all career stages.

The "Materials Needs for Energy Sustainability by 2050" series of panel sessions is jointly organized by the MRS Focus on Sustainability Subcommittee and the MRS Energy and Sustainability journal. The program, planned for Monday, December 2, from 5:15 pm to 6:15 $\mathrm{pm}$, focusing on plastics, will convene top experts to discuss scientific, technological, and sociological complexities relating to energy, the environment, and sustainability. This event will include an audience Q\&A as well as real-time interactive audience polling, so bring your smartphone and be ready to participate in this provocative session. This event is sponsored by the National Science Foundation and Thermo Fisher Scientific.

The National Science Foundation (NSF) will be participating at the Public Outreach Center. The Division of Materials Research will be present to schedule personal interviews with program directors to discuss diversity, sustainability, funding opportunities, and how to write a successful proposal.

Speed Coaching with the NSF Division of Materials Research will be featured in The Hub-Hall D on Tuesday from 9:00 am to 5:00 pm.

\section{For more information}

Registration for the 2019 MRS Fall Meeting includes a complimentary oneyear membership to MRS beginning January 1, 2020, through December 31, 2020. The deadline to preregister for the Meeting is November 15, 2019, 11:59 pm (ET). International travelers are reminded to allow ample time to obtain a visa, if needed.

For additional details about the Meeting, contact MRS Member Services: info@mrs.org (email) or 724-779-3003 (phone). Details of various events and activities will be available via the MRS Meeting App and in the Meeting \& Exhibit Guide available on-site. The MRS website can also be accessed for updated information on confirmed talks, details of special events, information on obtaining a visa, and preregistration: mrs.org/fall2019. 
HYNES CONVENTION CENTER, LEVEL 2

Tuesday, December 3 ..............11:00 am - 5:30 pm

Wednesday, December 4 ..........11:00 am - 5:30 pm

Thursday, December 5 ............10:00 am - 1:30 pm

abcr GmbH

Accurion, Inc.

Across International LLC

ACS Publications

Admiral Instruments

AdValue Technology, LLC

Advanced Polymer Materials Inc.

Advanced Research Systems, Inc.

AIP Publishing

AJA International, Inc.

Alemnis AG

Allevi, Inc.

Allwin21 Corp.

American Physical Society

ANCORP

Andeen-Hagerling, Inc.

Angstrom Engineering Inc.

Angstrom Sciences, Inc.

Angstrom Scientific Inc.

Anton Paar

Applied Surface Technologies

Asahi Spectra Co., Ltd.

Asylum Research,

an Oxford Instruments Company

attocube systems Inc.

Barnett Technical Services

BASi

Bio-Logic USA, LLC

Blue Wave Semiconductors, Inc.

Bruker

Bruker-AFM Probes

Bruker Nano

Cambridge University Press/

Materials Research Society

Carl Zeiss Microscopy, LLC

Cell Press

CELLINK

Chemat Scientific

Cobolt by HUBNER Photonics

CRAIC Technologies, Inc.

CrystalMaker Software Ltd.

CVD Equipment Corporation

DataPhysics Instruments USA Corp.

DCA Instruments, Inc.

DE GRUYTER

Delcom Instruments

Delong America Inc.

Digital Surf

Duniway Stockroom Corporation

Ebara Technologies, Inc.

Ebatco

Ecopia Corp.

ECS-The Electrochemical Society

EDAX Inc., AMETEK Materials

Analysis Division

Edinburgh Instruments Ltd.

Electron Microscopy Innovative Technologies

Electron Microscopy Sciences

Electron Optics Instruments LLC |

EmCrafts

Lake Shore Cryotronics, Inc.
Elsevier

Energetiq Technology, Inc.

Enli Technology Co., Ltd.

Ereztech LLC

ETRI (Electronics and

Telecommunications Research Institute)

Evactron ${ }^{\circledast}$ by XEI Scientific, Inc.

Extrel CMS, LLC

FemtoTools AG

Fischione Instruments

Frontiers

Furuya Metal Americas, Inc.

Gamry Instruments

Gatan

Geib Refining Corporation

Geowell Vacuum Co., Ltd.

Goodfellow Corporation

Graphene Square Inc.

Hamamatsu Corporation

HeatWave Labs, Inc.

Heidelberg Instruments Inc.

Herzan LLC

Hitachi High Technologies America, Inc.

HORIBA Scientific

Hummingbird Scientific

Huntington Vacuum Products

ID Quantique SA

InRedox LLC

Instec, Inc.

Integrated Dynamics Engineering

Integrated Surface Technologies

International Centre for Diffraction Data (ICDD)

International Union of Crystallography IONTOF

IOP Publishing

ISS, Inc.

Janis Research Company, LLC

Japan Science and Technology Agency

JASCO

JEOL USA, Inc.

JoVE

KA Imaging

Kaufman \& Robinson, Inc.

Keysight Technologies

KLA Corporation

Kleindiek Nanotechnik

KP Technology USA Inc.

Kurt J. Lesker Company

Linkam Scientific Instruments

LTS Research Laboratories, Inc.

M. Braun Inc.

Mad City Labs, Inc.

Malvern Panalytical

Materials Analysis Technology Inc.

(MA-tek Inc.)

Matheson Tri-Gas, Inc.

MilliporeSigma

MIT Press mrs.org/fall2019/exhibit
MKS Instruments

Montana Instruments

MSE Supplies LLC

MTI Corporation

Naieel Technology

Nano-Master, Inc.

NanoAndMore USA Corp.

NanoMagnetics Instruments

Nanosurf, Inc.

NANOVEA

NBM Design, Inc.

neaspec $\mathrm{GmbH}$

Neocera, LLC

NETA

NETZSCH Instruments

North America, LLC

Nor-Cal Products, Inc.

NT-MDT America, Inc.

OptiGrate, An IPG Photonics Company

OriginLab Corporation

Oxford Instruments America, Inc.

Park Systems Inc.

Photothermal Spectroscopy Corp.

PicoQuant Photonics

North America, Inc.

Pine Research Instrumentation, Inc.

Pittcon 2020

Plasmaterials, Inc.

Princeton Scientific Corp.

PROTO

Protochips, Inc.

PVD Products, Inc.

Qnami GmbH

Quantum Design, Inc.

R.D. Mathis Company

Radiant Technologies, Inc.

Raith America, Inc.

Renishaw Inc.

Rigaku

Rocky Mountain Vacuum Tech, Inc.

Royal Society of Chemistry

Royal Society Publishing
SAES Group

SAGE Publishing Ltd.

Science/AAAS

Scienta Omicron, Inc.

Scribner Associates Inc.

Seki Diamond Systems

Semilab USA LLC

Sensofar Metrology

Sine Scientific Instruments

SmarAct Inc.

Software for Chemistry \& Materials

SPECS-TII, Inc.

SPEX SamplePrep

SPI Supplies, Division of Structure

Probe, Inc.

Springer Nature

SPS-America

STAIB Instruments, Inc.

Strem Chemicals, Inc.

Super Conductor Materials, Inc.

Synton-MDP AG

TA Instruments

Taylor \& Francis Group

TDK-Lambda Americas-Neptune

Ted Pella, Inc.

TESCAN-USA

Thermo Fisher Scientific

THINKY USA, Inc.

Toshima Manufacturing Co., Ltd.

Trion Technology, Inc.

UC Components Inc.

ULVAC Technologies, Inc.

Vacuum Technology Inc.

VAT Group

Verder Scientific, Inc.

Vigor Tech USA, LLC

Wafer World Inc.

Wiley

WITec Instruments Corp.

J.A. Woollam Company, Inc.

World Scientific Publishing

Zurich Instruments USA, Inc.

\section{USER FACILITIES}

DIII-D National Fusion Facility

Environmental Molecular Sciences Laboratory (EMSL)

High Flux Isotope Reactor/Spallation Neutron Source

ISS U.S. National Laboratory

nanoHUB

Nanoscale Science User Facilities

National High Magnetic Field Laboratory

National Nanotechnology Coordinated Infrastructure

Nuclear Science User Facilities (NSUF)

PARADIM/Cornell NanoScale Facility

Penn State Materials Research Institute

Society for Science at User Research Facilities (SSURF)

Synchrotron Light Sources

UMass Lowell Core Research Facilities 